Portland State University

PDXScholar

$5-11-1979$

\title{
The Clinical Application and Practical Limitations of Bone Conducted Speech
}

Terry Scott Cochrane

Portland State University

Follow this and additional works at: https://pdxscholar.library.pdx.edu/open_access_etds

Part of the Speech and Hearing Science Commons

Let us know how access to this document benefits you.

\section{Recommended Citation}

Cochrane, Terry Scott, "The Clinical Application and Practical Limitations of Bone Conducted Speech" (1979). Dissertations and Theses. Paper 2789.

https://doi.org/10.15760/etd.2784

This Thesis is brought to you for free and open access. It has been accepted for inclusion in Dissertations and Theses by an authorized administrator of PDXScholar. Please contact us if we can make this document more accessible: pdxscholar@pdx.edu. 
AN ABSTRACT OF THE THESIS of Terry Scott Cochrane for the Master of Science in Speech Communication presented May. 11, 1979.

Title: THE CLINICAL APPLICATION AND PRACTICAL LIMITATIONS OF BONE CONDUCTED SPEECH

APPROVED BY MEMBERS OF THE THESIS COMMITTEE:

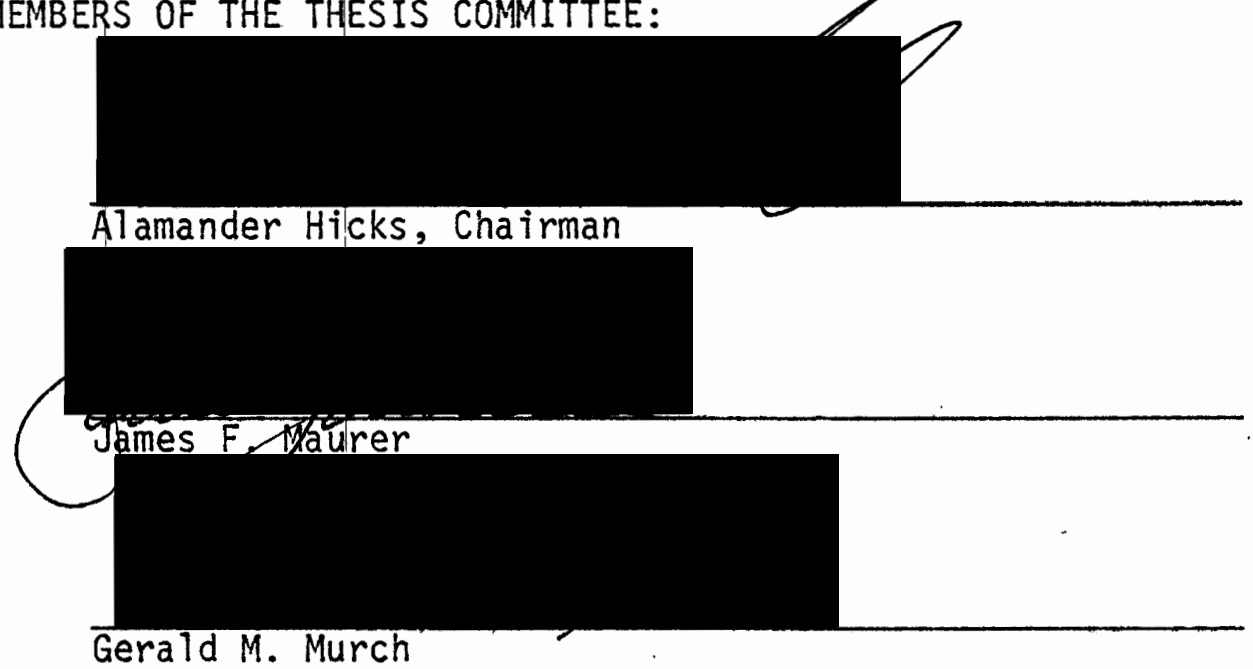

The purpose of this study was to investigate the effects of increased intensity on the bone conducted speech discrimination ability of normal listeners utilizing standard audiological equipment. The NU-6 word lists were utilized to test the bone conducted speech discrimination skills of ten normal hearing subjects, 21 to 30 years of age, on standard clinical equipment. Both the hearing levels (dB HL) and the sensation levels ( $d B S L$ ) of the test administration were considered. In genera1, it was recommended that $100 \mathrm{~dB} \mathrm{HL}$ is the most appropriate dial setting for the administration of bone conducted speech 
discrimination tests even though comparable speech discrimination scores may be obtained with a $95 \mathrm{~dB} \mathrm{HL}$ dial setting. This study indicates that the most appropriate sensation levels for the administration of bone conducted speech discrimination tests are 55 and $60 \mathrm{~dB} \mathrm{SL}$. Most normal listeners can be expected to achieve a $55 \mathrm{~dB}$ sensation level at the limits of the speech audiometer (100 dB HL). Additionally, it was found that when bone conducted speech discrimination tests are administered at levels of less than $55 \mathrm{~dB} \mathrm{SL}$, the results may be compromised by variances that occurred in this normal hearing sample. Therefore, the clinical audiologist should accept bone conducted speech discrimination results as valid only when the scores obtained at 40 , 45 and $50 \mathrm{~dB}$ sensation levels are within the limits of clinical normality ( $90 \%$ or better).

Recommendations for further research are discussed. 
THE CLINICAL APPLICATION AND PRACTICAL LIMITATIONS OF BONE CONDUCTED SPEECH

by

TERRY SCOTT COCHRANE

A thesis submitted in partial fulfillment of the requirements for the degree of

\author{
MASTER OF SCIENCE \\ in \\ SPEECH \\ with emphas is in Speech Pathology \\ and Audiology
}

Portland State University

1979 
This thesis is dedicated to my precious wife Vickie, who, without complaint, continued to be loving and devoted under the most adverse circumstances with very little thanks or recognition. 
TO THE OFFICE OF GRADUATE STUDIES AND RESEARCH:

The members of the Committee approve the thesis of Terry Scott Cochrane presented May 11, 1979.

A7amander Hicks, Chairman

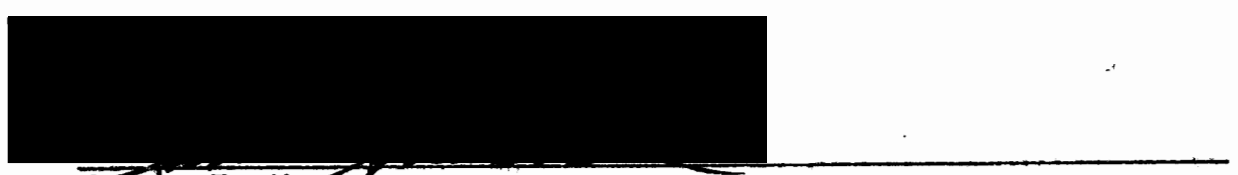

James F. Maurer

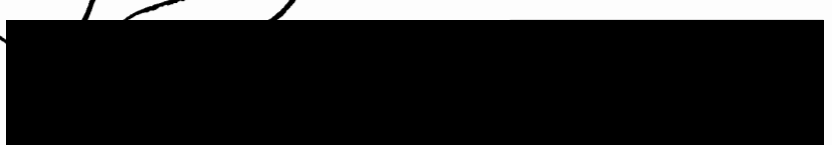

Gerald M. Murch

APPROVED:

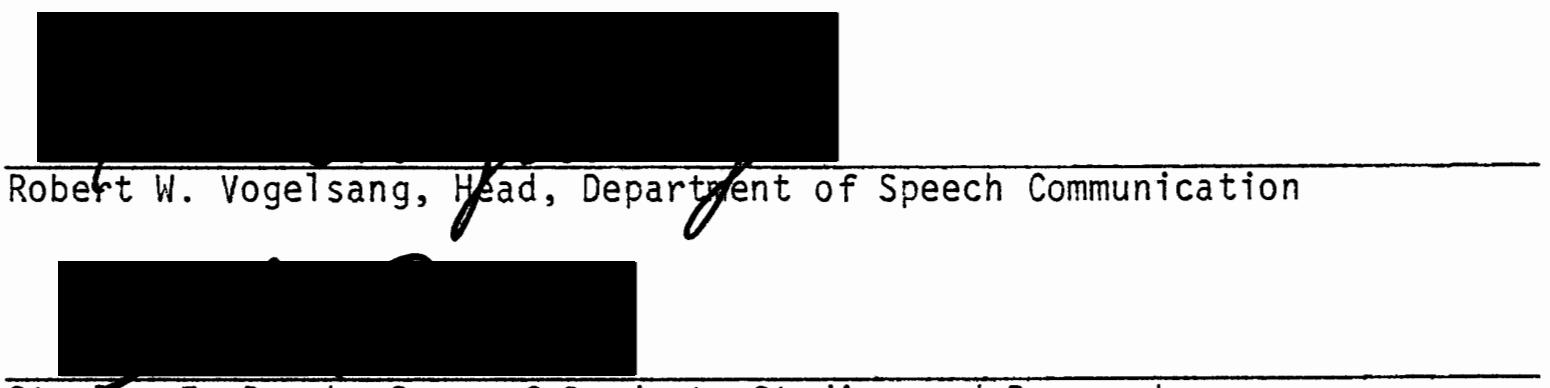

Stanley E. Rauch, Dean of Graduate Studies and Research 


\section{ACKNOWLEDGEMENTS}

I wish to express my sincere appreciation and deep gratitude to Dr. Al Hicks, my thesis committee chairman, who made this investigation a success through his many hours of hard work, constructive criticism, helpful suggestions, attention to detail, and devotion to a student who desperately needed the help.

I also wish to thank $D r$. James F. Maurer who participated on my thes is committee, lent me his calculator, and gave freely of his advice and time during this investigation.

I would like to acknowledge the support and encouragement of Dr. Gerald M. Murch who graciously agreed to interrupt a busy schedule to participate on my thesis committee.

I am indebted to Beverly Schnabel, a friend and colleague, who assisted in the pilot study, carried the clinic load and helped me keep abreast of my coursework during this investigation.

I want to remember those ten dedicated Audiology and Speech Pathology students who adjusted their schedules to participate in about two and a half hours of difficult testing.

Finally, to Gene, Darla, Teresa, Patty and Tony, who let their daddy study and did not complain when he was gone, thank you. And, a very special thanks to my wife Vickie for her dedication, sympathy, encouragement and late night dinners. 
TABLE OF CONTENTS

PAGE

ACKNOWLEDGEMENTS . . . . . . . . . . . . . . . ${ }_{i y^{\prime}}$ LIST OF TABLES . . . . . . . . . . . . . . . . . vi vi LIST OF FIGURES . . . . . . . . . . . . . . . vi i CHAPTER

I INTRODUCTION .......................... I

II REVIEW OF THE LITERATURE .............. . . 3

BONE CONDUCTED PURE TONE TESTS .......... . 3

Reliability of Bone Conducted Tests ..... . 4

Procedural Variables............ 5

Elimination of the Non-Test Ear ....... 7

Bone Conduction Equipment Calibration . . . . 7

AIR CONDUCTED SPEECH TESTS ............. . . . 9

Speech Reception Threshold Tests ........ 10

Speech Discrimination Tests ......... 11

Masking for speech ........... 13

BONE CONDUCTED SPEECH TESTING .......... 14 PURPOSE ...................... 17

Rationale ............. 17

III METHODS ..................... 19

Subjects.............. 19

Procedure ............. 19 
PAGE

Instrumentation ............. . 21

Calibration ................ 21

IV RESULTS ............... 23

V SUMMARY AND CONCLUSIONS ............ 30

Summary ............. . . 30

Conclusions ............. . . 34

REFERENCES .................... . . 37 


\section{LIST OF TABLES}

TABLE

PAGE

I Percentage of Correct Responses in Normal Listeners'

Bone Conducted Speech Discrimination at Five

Hearing Levels... . . . . . . . . . . 24

II Percentage of Correct Responses in Normal Listeners'

Bone Conducted Speech Discrimination at Five

Sensation Levels . . . . . . . . . . . . 27 


\section{LIST OF FIGURES}

FIGURE

PAGE

1. Means and Standard Deviations of Percentage of Correct Responses at Five Hearing Levels . . . . 25

2. Means and Standard Deviations of Percentage of Correct Responses at Five Sensation Levels . . . 29 


\section{CHAPTER I}

\section{INTRODUCTION}

Clinical audiology as a profession must continue to move forward and grow not only in the number of professionals but also in the refinement of its clinical techniques. Katz (1978) suggests that clinical audiology has two divisions of labor, diagnostic and rehabilitative audiology. According to Katz, diagnostic audiology deals with evaluation and is primarily concerned with site of lesion testing, while rehabilitative audiology deals with the management of the hearing impaired patient. However, most clinical audiologists provide services in both areas and the prognostic statement provides an appropriate link between these two services. That is, determination of the site of lesion is of little or no value if the audiologist cannot make appropriate medical referral or provide non-medical intervention, since both of these alternatives presuppose a reasonable knowledge of potential etiologies and the prognosis for a normal recovery. Additionally, the prognostic statement is only as refined as the diagnostic test data on which it is based.

The differentiation of the relative severity of conductive (middle ear) lesions is a prime example of diagnostic test refinement. Dirks (1978) notes that the primary interest in bone conduction testing has been to establish the presence or absence of a conductive or middle ear hearing loss. Once the presence of a conductive lesion has been 
confirmed, the bone conduction test results are important for making decisions concerning surgery and the potential postoperative improvement. Traditionally, this prognosis has been based on the magnitude of the discrepancy between air and bone conduction pure tone threshold data obtained through voluntary responses. This type of testing has a number of limitations; it only tests hearing at a few discrete frequencies instead of the full range of hearing, the patient may not be able to identify the ear under test, and not all populations of hearing impaired patients respond reliably to pure tones. However, the most important limitation is that pure tone tests do not accurately reflect a patient's ability to process speech through either the conductive or the neurological pathways. Therefore, when an audiologist makes decisions on the basis of pure tone air and bone conducted tests alone, he is somewhat limited in the kinds of statements he can make concerning patient success.

One solution to this problem is through the use of air and bone conducted speech tests. These tests can give the audiologist an estimate of the patient's ability to process speech. The air conducted speech testing procedures have been standardized and used in the clinic for a number of years and have proved to be a very useful clinical tool. However, this is not true of the bone conduction speech tests. Bone conducted speech testing reportedly originated with the work of Tato and Alfaro as early as 1949 (Stockdell, 1974) but little research has been generated in this area and these tests have not achieved popularity in the clinical setting. The reason for this slow development is best understood by reviewing the history of bone conduction test procedures. 


\section{REVIEW OF THE LITERATURE}

Bone conduction testing consists of introducing sound stimuli to the auditory mechanism through the bones of the skult. Placement of the bone oscillator may be at any point on the skull but the two most common placements are near the center of the forehead or on the mastoid process of the temporal bone behind the pinna of the ear under test. The advantage of the bone conducted test is that sound stimuli bypass the middle ear and thereby el iminate the conductive mechanism from the cochlear response. Since the mode of cochlear excitation is identical for both air and bone conducted stimuli, it is well to examine the underlying assumptions associated with cranial transmission of sound.

\section{BONE CONDUCTED PURE TONE TESTS}

The two assumptions underlying all bone conduction testing are that the bone conducted stimuli measure the integrity of the sensory neural system and that air conducted signals measure the integrity of the entire system (Dirks, 1978). Thus, by observing the discrepancy between air conducted stimuli and bone conducted stimuli, the clinician can assess the integrity of the conductive mechanism. This ability to separate the air conduction pathway from the sensory pathway makes bone conducted testing a useful clinical tool. Recognizing this fact, Carhart (1950) argued strongly for the adoption of pure tone bone 
conducted tests in routine clinical audiometry. At that time, bone conducted tests were not widely used in the clinic due to the difficulty controlling procedural variables and signal parameters.

Carhart (1950) mentioned four variables which limit the clinical applicability of bone conducted tests; doubt in the reliability of bone conducted thresholds, difficulty in calibrating audiometers, inadequate testing conditions, and control of masking in the non-test ear. After several years of bone conducted pure tone testing in the clinic, many of the same problems still exist. Twenty-eight years later, Dirks (1978) presented his list of variables; participation of the non-test ear in the bone conducted response, difficuities specifying the output of the bone conduction oscillator, problems associated with masking the non-test ear, and equipment and procedural variables. As can be seen, these problems are essentially unchanged even though there has been considerable published research in this area. The limited progress in eliminating these problems is best understood by examining the complexity of these variables individually.

\section{Reliability of Bone Conducted Tests}

Carhart and Hayes (1949) investigated the test-retest reliability of pure tone bone conducted thresholds on 250 patients who represented a wide variety of hearing losses. These patients were given pure tone threshold tests approximately one month apart and their data revealed less variability in the bone conducted test-retest results than in air conducted results. Thus, Carhart and Hayes argued that the bone conducted threshold tests could be very reliable when proper precautions are 
taken to insure control of the bone conducted testing techniques.

In another study, Dirks (1964a) assessed the test-retest reliability under a much wider variety of conditions. He assessed reliability using different bone conduction oscillators, three different types of masking noise, and forehead or mastoid placement of the oscillator. His findings suggest that bone conducted tests are repeatable regardless of the type of vibrator used or the application force of the vibrator (a11 forces exceeded $400 \mathrm{gm}$ ). The forehead placement was found to be more reliable than the mastoid placement, although, not clinically significant and he felt that the advantage gained in terms of intensity with a mastoid placement outweighs the greater reliability of a forehead placement. Finally, Dirks did find a significant difference in test-retest reliability when masking is employed for testing. This difference, a $2 \mathrm{~dB}$ discrepancy, would have little effect in the clinical setting where a $5 \mathrm{~dB}$ increment is employed for testing. Dirks concluded that when equipment and clinical variables are brought under control, bone conduction testing can be a reliable clinical instrument.

\section{Procedural Variables}

One procedural variable is the method used in obtaining air or bone conducted pure tone threshold. Carhart and Jerger (1959) studied this problem by comparing three different clinical methods for obtaining a threshold; an ascending technique, a descending technique and a combination of the two techniques. Their results suggest that while there is essentially no difference in the three techniques, the ascending technique should be adopted to insure uniformity in audiological 
testing procedures. In this technique, the examiner presents the initial stimulus below the patient's threshold and increases the intensity of each successive stimulus until a response is obtained. Additional$1 y$, Carhart and Jerger recommended that each presentation be one or two seconds in duration followed by a pause of two to three seconds. Such a procedure would avoid the effects of fatigue.

A second procedural variable is the point on the skull which is selected for oscillator placement. Studebaker's (1962a) investigation of this problem compared test results obtained by placing the bone conduction oscillator at the forehead, vertex and mastoid positions. His results indicated that the lowest thresholds were obtained with a mastoid placement and the mastoid position was less affected by middle ear pathologies. However, while it was noted that the forehead produced less intersubject variability than the mastoid position, Studebaker felt that the forehead placement would increase the validity and the reliability of bone conduction measurements in clinical practice.

When using a mastoid placement of the bone vibrator, the manner of positioning becomes an important test parameter. It is a well known fact that allowing the vibrator to touch the pinna enables the subject to feel the vibration thus invalidating the test. Bavosi and Rupp (1973) investigated five methods for placing the vibrator on the mastoid bone and concluded that the clinical method was just as reliable as more involved procedures when care is taken to avoid contact with the pinna.

Although a tradeoff may be made in terms of reliability, most clinics have adopted the mastoid placement of the bone conduction 
oscillator over the forehead position in order to ga in the advantage of increased intensity. In addition, most clinics have adopted the suggestions of Carhart and Jerger (1959) and now employ an ascending technique for establishing a pure tone threshold.

\section{Elimination of the Non-Test Ear}

One of the problems which consistently plagues all audiometric testing is the elimination of the non-test ear. This problem has special significance in the case of bone conducted tests since both cochleae are being driven simultaneousiy by the bone conduction oscillator. This testing situation mandates that a masking noise be applied to the non-test ear in order to validate the threshold of the ear under test (Hood, 1962). Hood maintains that it is important to select an efficient masking noise which el iminates the non-test ear with a minimum intensity level since it is occasionally necessary to utilize uncomfortably high levels of noise. Of the types of noise presently available on clinical audiometers, it has been shown that narrow bands of noise are the most efficient for masking pure tones (Studebaker, 1962b; Sanders and Rintleman, 1964). For this reason, clinical pure tone bone conducted testing is routinely done utilizing narrow band masking in the non-test ear.

Bone Conduction Equipment Calibration

A final consideration in pure tone bone conduction testing is that of equipment variables. In order to make valid statements concerning a patient's hearing, it is necessary that the test equipment and signals be accurate and consistent throughout the industry. Prior to 
the development and adoption of formal bone conduction calibration procedures, most clinics employed Carhart's (1950) method. Carhart recommended an audiometer bone conduction calibration technique utilizing normal hearing and sensorineural hearing loss listeners to obtain a correction factor. This method has been used clinically until the recent advent of an artificial mastoid which allows a more accurate electracoustic measurement.

The problems complicating the development of an artificial mastoid were twofold; the impedance values of the human forehead and mastoid were largely unknown and the materials necessary to build such a device varied dramatically with temperature and age (Dirks, 1974). However, within the last ten years, two types of artificial mastoid have emerged; the British mastoid which is composed of laminated silicone and butyl rubbers and the Beltone mastoid which utilizes an airdamping technique for simulating the human sku11 impedance. In 1972, the American National Standards Institute published their standard (ANSI, S3,13-1972) which formally set forth human skul1 impedance values, the cross sectional area for a circular tipped oscillator $\left(1.75 \mathrm{~cm}^{2}\right)$ and the static force needed to validate oscillator outputs (550 grams). This new standard was appendicized with the mechanica] impedance values to be used with the Beltone artificial mastoid for the most widely used bone conduction oscillator (Radioear, Model B 70-A).

Although the new standard has been adopted for clinical use, it does not have impedance values for the now widely used Bruel and Kjaer artificial mastoid. In an effort to remedy this situation, wilbur 
(1972) made several comparisons between the Beltone and Bruel and Kjaer mastoid utilizing four Radioear oscillators. By averaging her data with previously reported data, she produced a table of values which are consistent with the ANSI standard and may be used when calibrating bone oscillators with the Bruel and Kjaer artificial mastoid.

Thus, it appears that variables such as clinical procedures, masking of the non-test ear and equipment calibration involved with pure tone bone conduction testing can be specified and dealt with in a clinical testing environment. It is this signal specificity and variable control which makes pure tone bone conducted testing a viable clinical tool. Bone conducted speech testing, on the other hand, introduces a new and more complex set of variables which must be considered. The complexity of bone conducted speech testing may best be appreciated by first considering the nature of and the principles involved in air conducted speech testing.

\section{AIR CONDUCTED SPEECH TESTS}

Clinical speech testing presupposes the existence of an articulation function curve which depicts how well a listener understands speech as a function of intensity. By plotting the intensity of the speech on one axis (abscissa) and the number of $i$ tems understood on the other axis (ordinate), a curve can be plotted which starts from a point where nothing is understood (low intensity) and proceeds to a point where a normal listener can understand all of the items correctly (higher intensity). According to Carhart (1951), an articulation function is a valuable clinical tool for assessing communication 
skills in the hearing impaired. For example, some of the hearing impaired persons may simply require increased intensity to understand speech while others may not understand speech well regardless of the presentation levels to plot a complete articulation function, clinical practice constraints may limit this graph to only two or three points in some cases.

There are two presentation levels which are of considerable interest for speech testing. The first is the intensity level where speech just becomes intelligible and the second is the intensity level at which maximum intelligibility is obtained. There are two generally accepted tests which may be used for this purpose; the speech reception threshold test and the speech discrimination test.

\section{Speech Reception Threshold Tests}

The intensity level at which speech first becomes intelligible is known as the speech reception threshold test (SRT) and is defined as the intensity where $50 \%$ of the speech items are understood correctly (Carhart, 1951). To be a good test for this purpose, Carhart maintains that the words must approximate connected speech and should be approximately equally audible. While different types of speech materials have been used for SRT testing, the most common speech material in the clinic for this purpose is the spondee word lists (Hopkinson, 1978). Spondees are two syllable words in common use which have equal phonetic emphasis on each syllable.

The SRT has two primary functions in the clinic; it gives the audiologist an estimate of the lower limit of a patient's ability to 
understand speech and it serves as a reliability check on the pure tone tests that have been administered. Carhart's (1946) research found a high degree of correlation between the SRT and an average of the pure tone thresholds for the frequencies 512,1024 and $2048 \mathrm{~Hz}$. However, today the average pure tone threshold is based on three slight$1 y$ different frequencies, 500,1000 and $2000 \mathrm{~Hz}$.

\section{Speech Discrimination Tests}

The speech discrimination test is used to assess a patient's abiljty to understand speech when the listening intensity level is optimal (Carhart, 1952). According to Carhart, a good speech discrimination test must contain the critical phonemic elements of a language, be distributed as proportionately in the test as the language they represent and must occur as often in the language as the test. In a later report, Carhart (195I) suggested that the most important consideration when choosing a discrimination test is the linguistic background of the patient since unfamiliar materials are more difficult to understand. Carhart recommended the use of monosyllabic materials for discrimination testing because they are relatively nonredundant, unpredictable and less confusing than nonsense syllables. He also noted that the only valid estimate of discrimination ability is when a $100 \%$ score is achieved. That is, with less than $100 \%$, there is no way of knowing whether the maximum score could be achieved at another intensity.

Two variables in speech discrimination testing are the method of presenting word lists, and the influence of the examiner in scoring the 
test responses. Brandy (1966) studied the reliability of speech discrimination as it related to the speaker's voice and concluded that there is enough day-to-day variation in a speaker's voice to influence the outcome of the test. Brandy recommended the use of recorded word lists to obtain the most valid results. Concerning the examiner's influence on the test results, Merrell and Atkinson (1965) found significant differences between the written responses of the patient and the scores awarded by the panelists who listened to the recorded responses. Therefore, these authors recommended the use of written responses to remove the audiologist's hearing as a variable in the discrimination test.

The most popular discrimination tests used in the clinic are the Harvard Psychoacoustic Laboratories PB-50 (PAL PB-50) and the Central Institute for the Deaf W-22 (CID W-22) word lists (Goetzinger, 1978). However, according to Goetzinger, the PAL PB-50 lists have been criticized because they may not be phonetically balanced and contain many unfamiliar materials and the CID W-22 lists are considered to be too easy for differential diagnosis. In an effort to overcome these difficulties, Carhart and Tillman developed another set of monosyllabic word lists known as the Northwestern University auditory test number 6 (NU-6) (Goetzinger, 1978). Goetzinger reports that the interest reliability of the NU-6 word lists is high with both normal and sensory neural subjects.

Recently, the NU-6 word lists have been made available on commercial tape recordings through Auditec of St. Louis. On these prerecorded lists, the speech reception threshold tests are comprised of 
50 spondaic words per list. The speech discrimination materials consist of 50 monosyllabic, phonetically balanced words per list. There are four different discrimination word lists which have been randomly reordered 4 times for a total of 16 lists. Beattie, et al. (1977) compared the commercial recordings of the CID W-22 and the NU-6 word 1 ists and concluded that these recordings were essentially equal.

Masking for speech

Studebaker (1967) investigated the need for masking in speech testing and reasoned that even though the sensation level was lower in the non-test ear, it may be high enough to affect the discrimination score in the test ear. Thus, he recommended the use of masking whenever the presentation level of the speech exceeded the bone conduction threshold in the non-test ear by $40 \mathrm{~dB}$ or more.

When utilizing masking for speech, it is important to consider the type of masking noise to be used. Wilson, et a1. (1973) studied the effects of three types of masking noise and concluded that while speech noise and wide band noise will both mask speech linearly, speech noise is about $8 \mathrm{~dB}$ more effective for most types of test materials. Further, their data indicated that while narrow band noise would mask speech, the relationship between the intensity of the speech and the intensity of the noise was not linear. Wilson, et al. recommended the adoption of speech noise as the noise of choice for clinical speech testing with wide band noise being a second choice when speech noise is not available.

Thus, the refinement of speech masking protocol has greatly 
enhanced air conducted speech testing as a clinical tool and allows the audiologist to better understand the ramifications of speech testing. However, bone conducted speech testing has not been widely employed in the clinic. It is, therefore, necessary to consider the curm rent research in bone conducted speech testing.

\section{BONE CONDUCTED SPEECH TESTING}

Tato and Alfaro are credited with being the first to use bone conducted speech tests. They tested the bone conducted speech discrimination of otosclerotic patients and found the bone conducted speech tests to be superior to air conducted speech tests for predicting pastoperative success of their patients (Stockde11, 1974). However, little interest was given to the subject of bone conducted speech testing until the work of Goetzinger and Proud (1955). Unaware of Tato and Alfaro's: work, Goetziner and Proud attempted to determine the relationship between the bone conducted average pure tone threshold (APT) and the bone conducted speech reception threshold (SRT). These researchers found a high degree of correlation between the bone conducted APT and bone conducted SRT, and this relationship was only slightly poorer than the same relationship by air conduction. They recommended using the bone conducted SRT as a reliability check on the bone conducted pure tone test results and suggested that bone conducted speech might be useful when testing young children where adequate pure tone thresholds could not be obtained. Although bone conducted speech discrimination tests were not used in their study, they suggested that such tests might be profitably used to predict the postoperative 
success of otosclerotic patients.

Robinson and Kasden (1970) used standard recorded word lists (CID $W-1$ and $W-22$ ) presented at a $40 \mathrm{~dB}$ sensation level to investigate bone conducted speech. On the bas is of pre- and postoperative speech discrimination skills in a large group of otosclerotic patients, Robinson and Kasden conciuded that the bone conducted preoperative speech discrimination test is a reliable predictor of the patient's postoperative air conducted speech discrimination skills.

In a follow-up study, Kasden and Robinson (1973) compared the bone conducted speech discrimination scores of an otosclerotic group of patients to a large group of patients with other conductive pathologies. In the otosclerotic group, their findings confirmed that bone conducted speech discrimination tests were highly reliable in predicting postoperative success. However, Kasden and Robinson found little or no difference in the preoperative air and bone conducted speech discrimination scores in patients with other conductive pathologies suggesting that bone conducted speech discrimination tests may be unnecessary in these cases.

Klodd and Edgerton (1977) investigated the effect of occluding the non-test ear for bone conducted speech tests using both a forehead and a mastoid placement. Their findings indicated that the mastoid placement was more sensitive than the forehead placement in both the occluded and unoccluded listening conditions. Additionally, the effect of occluding the ear canal of the non-test ear in the mastoid condition was smaller and less variable. While they did not actually use masking in the study, they suggest that $18 \mathrm{~dB}$ of masking would be required to 
overcome the occlusion effect in the mastoid condition, and $23 \mathrm{~dB}$ of masking is necessary in the forehead condition. Klodd and Edgerton concluded that the mastoid placement is the position of choice for bone conducted speech testing due to the extended range of the oscillator and the smaller occlusion effect in that condition.

Barry and Gaddis (1978) studied the validity of adding an amplifier to the bone conduction circuit to increase the power in a standard bone vibrator (Radioear, Model B 70-A) for bone conducted speech testing. In this investigation, electroacoustic frequency response characteristics of the bone conduction oscillator and the speech discrimination skills of normal listeners using standard recorded word 7ists (NU-6) were analyzed. The results of the electroacoustic measures indicated that a substantial amount of total harmonic distortion was present at $105 \mathrm{~dB} \mathrm{HL}$ and the speech discrimination scores of normal listeners depreciated dramatically by $115 \mathrm{~dB} \mathrm{HL}$. Barry and Gaddis concluded that the upper limits for valid bone conducted speech testing is $100 \mathrm{~dB} \mathrm{HL}$. They reasoned that beyond that point there is enough distortion present in the bone conduction oscillator to adversely affect the discrimination scores of patients with defective hearing even though normal 1 isteners can discriminate fairly well beyond this limit. Thus, increased power to the oscillator was contraindicated for bone conducted speech testing.

The bone conducted speech studies, thus far, have presented clinically confusing results. That is, there seems to be wide general agreement that the bone conducted speech reception threshold test is a useful and valid measure. However, the evidence presented by Barry 
and Gaddis (1978) suggests that there are limits to bone conducted speech tests which were not previously reported in the literature. Further, many of these bone conducted speech studies utilized nonstandard equipment which is not generally available in the clinic. In light of these facts, it is not surprising that audiologists have been slow to adopt bone conducted speech testing techniques.

\section{PURPOSE}

The purpose of this investigation was to study the effects of increased intensity on a normal listener's bone conducted speech discrimination ability utilizing standard audiological equipment. Another specific interest was whether unmodified clinical equipment could be validly used for bone conducted speech discrimination testing and what are the practical limits of such tests?

\section{Rationale}

It is well established that bone conducted speech discrimination tests have been used by several investigators to predict the postoperative air conducted speech discrimination ability of otosclerotic patients. To date, however, norms for bone conducted speech discrimination are not known utilizing normal listeners and standard clinical test equipment. Further, the optimum listening levels and equipment limits for clinical bone conducted speech have not been established. Thus, it seems propitious to investigate bone conducted speech discrimination skills of the normal listeners utilizing standard clinical equipment.

The transmission characteristics of the human skull utilizing a 
bone conduction oscillator are also largely unknown. For example, the normal listener's discrimination skills could well vary as a function of skull transmission rather than the sensation level of the speech. Thus, a normal listener's bone conducted speech discrimination ability could well vary as a function of increased intensity level. 


\section{CHAPTER III}

\section{METHODS}

\section{Subjects}

Ten subjects, 8 female and 2 male, were selected from a pool of volunteers enrolled in Speech and Hearing Science courses at Portland State University. Participants ranged in age from 21 to 30 years and signed a human subjects Informed Consent form prior to any testing. All subjects utilized in this study had normal hearing as measured by standard air conducted pure tone and speech testing procedures. No subject was used in this study who reported a familial history of deafness, positive record of ear disease or manifested any abnormal auditory processing difficulty. Strict attention was given to good speech discrimination ability ( $90 \%$ or better in the test ear) and the average pure tone thresholds were consistent with the speech reception thresholds and all thresholds were $5 \mathrm{~dB}$ or better.

\section{Procedure}

All potential subjects were given an audiological assessment utilizing standard clinical procedures and every subject completed a Case History form to confirm their eligibility for this investigation. Each subject's ears were assigned an individual number (right ear odd, left ear even) to maintain anonymity for all experimental data collected.

Prior to the administration of the experimental tests, the 
subjects were seated at a desk in the audiological test suite and the instructions for the bone conduction speech reception threshold test were presented to each subject on a printed card. These instructions were read out loud to each subject and they were given an opportunity to ask any questions concerning any aspect of the experimental procedure. The bone conduction oscillator was placed on the mastoid process behind the test ear and the bone conducted speech reception threshold test was administered in the test suite. The subjects were instructed in a similar manner before the administration of the bone conducted speech discrimination tests. At this time, subjects were provided with answer sheets for their written responses and an earphone was placed over the non-test ear. During the administration of the bone conducted speech discrimination tests a five minute rest period was mandatory whenever a test was to be delivered at a sensation level lower than the test just preceding it. Further, a minimum rest period of one day was required before any bone conducted tests were administered in the second ear.

A11 bone conducted speech testing material consisted of 16 prerecorded NU-6 speech discrimination lists (Auditec of St. Louis). These bone conducted speech discrimination tests were administered in $5 \mathrm{~dB}$ increments from $40 \mathrm{~dB} \mathrm{SL}$ to the limits of the audiometer (100 dB HL). The sensation levels were selected in random order utilizing a table of random numbers (Mendenhal1, 1975).

Speech noise was used for masking the non-test ear since its spectral composition is limited to the speech frequencies (500 through $2000 \mathrm{~Hz}$ ). The intensity of the speech masking noise in the non-test 
ear was determined by adding $30 \mathrm{~dB}$ to the sensation level of the experimental stimuli being presented to the ear under test. This level was sufficient to overcome the approximately $18 \mathrm{~dB}$ occlusion effect (Klodd and Edgerton, 1977) and still provide a favorable signal to noise ratio (10 to $20 \mathrm{~dB}$ ) in the test ear.

Instrumentation

All tests took place in a double walled sound treated room (International Acoustics Corporation, Model 1403) and all tests were conducted through a dual channel clinical audiometer (Maico, Model 24-b). All air conducted stimuli were presented through a standard clinical set of earphones (Telephonics, Model TDH-39) mounted in foam rubber cushions (Acoustic Research, Model MX 41/AR). A standard clinical bone conduction oscillator (Radioear, Model B 70-A) was utilized to deliver all experimental stimuli. Speech test material consisted of prerecorded NU-6 word lists (Auditec of St. Louis) delivered to the audiometer by a reel-to-reel stereo tape recorder (Sony, Model TC-377) such that the audiometer's calibrated tape circuit could be utilized to insure the electrical and acoustic integrity of all experimental stimuli.

\section{Calibration}

The audiometer calibration and the stability of the artificial mastoid (Bruel and Kjaer, Model 4930) were checked prior to each experimental session. The output at the earphones was electroacousticalIy calibrated to reflect current ANSI standards using a precision sound level meter (Bruel and Kjaer, Model 2203) and an artificial ear 
(Bruel and Kjaer, Model 4152). In addition, the output of the bone conduction vibrator was electroacousticaliy adjusted to reflect the most recent ANSI standards including the correction factors provided by Wilbur (1972). A prerecorded segment of $500 \mathrm{~Hz}$ and $1000 \mathrm{~Hz}$ pure tones was utilized to check the calibration and linearity of the experimental equipment. 


\section{CHAPTER IV}

\section{RESULTS}

The results of this investigation suggest that there are clinically definable equipment limits and optimum listening levels for bone conducted speech discrimination testing. The data indicates that bone conducted speech discrimination performance is affected by the intensity at which the signal is presented or the audiometer dial setting (dB HL). Table I presents the combined performance of al1 19 test ears for each experimental 1 istening condition. Six ears were tested at 80 $\mathrm{dB} H \mathrm{HL}$, fifteen at $85 \mathrm{~dB} H \mathrm{HL}$ and all 19 ears were tested at 90,95 and $100 \mathrm{~dB} \mathrm{HL}$. As can be seen, the mean performance scores on the bone conducted speech discrimination tests improved with increased intensity at each $5 \mathrm{~dB}$ HL increment from a lower mean percentage of correct responses $(93.00 \%)$ at $80 \mathrm{~dB} H \mathrm{HL}$ to the highest mean performance $(98.84 \%)$ at $100 \mathrm{~dB}$ HL. The Student's t test (Mendenhall, 1975) was utilized to determine statistical significance between the optimal mean speech discrimination performance at $100 \mathrm{~dB} \mathrm{HL}$ and the mean performance at each of the other four hearing levels. Statistically, the mean performances were found to be significantly poorer at $80 \mathrm{~dB} \mathrm{HL}(P<.005)$ and $85 \mathrm{~dB} H L(P<.025)$ than at $100 \mathrm{~dB} H \mathrm{HL}$. However, there were no statistically significant differences between the mean performances at 100 $\mathrm{dB} H \mathrm{~L}$ and the performances at 90 and $95 \mathrm{~dB} H \mathrm{HL}$. 


\section{TABLE I}

\section{PERCENTAGE OF CORRECT RESPONSES IN NORMAL LISTENERS' BONE CONDUCTED SPEECH DISCRIMINATION AT FIVE HEARING LEVELS}

\begin{tabular}{|c|c|c|c|}
\hline $\begin{array}{l}\text { Sensation } \\
\text { Levels } \\
\end{array}$ & $\begin{array}{l}\text { Sample } \\
\text { Size }\end{array}$ & $\begin{array}{l}\text { Mean } \\
\% \text { scores }\end{array}$ & $\begin{array}{l}\text { Standard } \\
\text { Deviations }\end{array}$ \\
\hline 80 & 6 & $93.00 \%$ & $5.48 \%$ \\
\hline 85 & 15 & $95.60 \%$ & $4.08 \%$ \\
\hline 90 & 19 & $97.89 \%$ & $2.71 \%$ \\
\hline 95 & 19 & $98.21 \%$ & $1.99 \%$ \\
\hline 100 & 19 & $98.84 \%$ & $2.43 \% *$ \\
\hline
\end{tabular}

*This larger standard deviation resulted from. one subject obtaining a score of $90 \%$. 


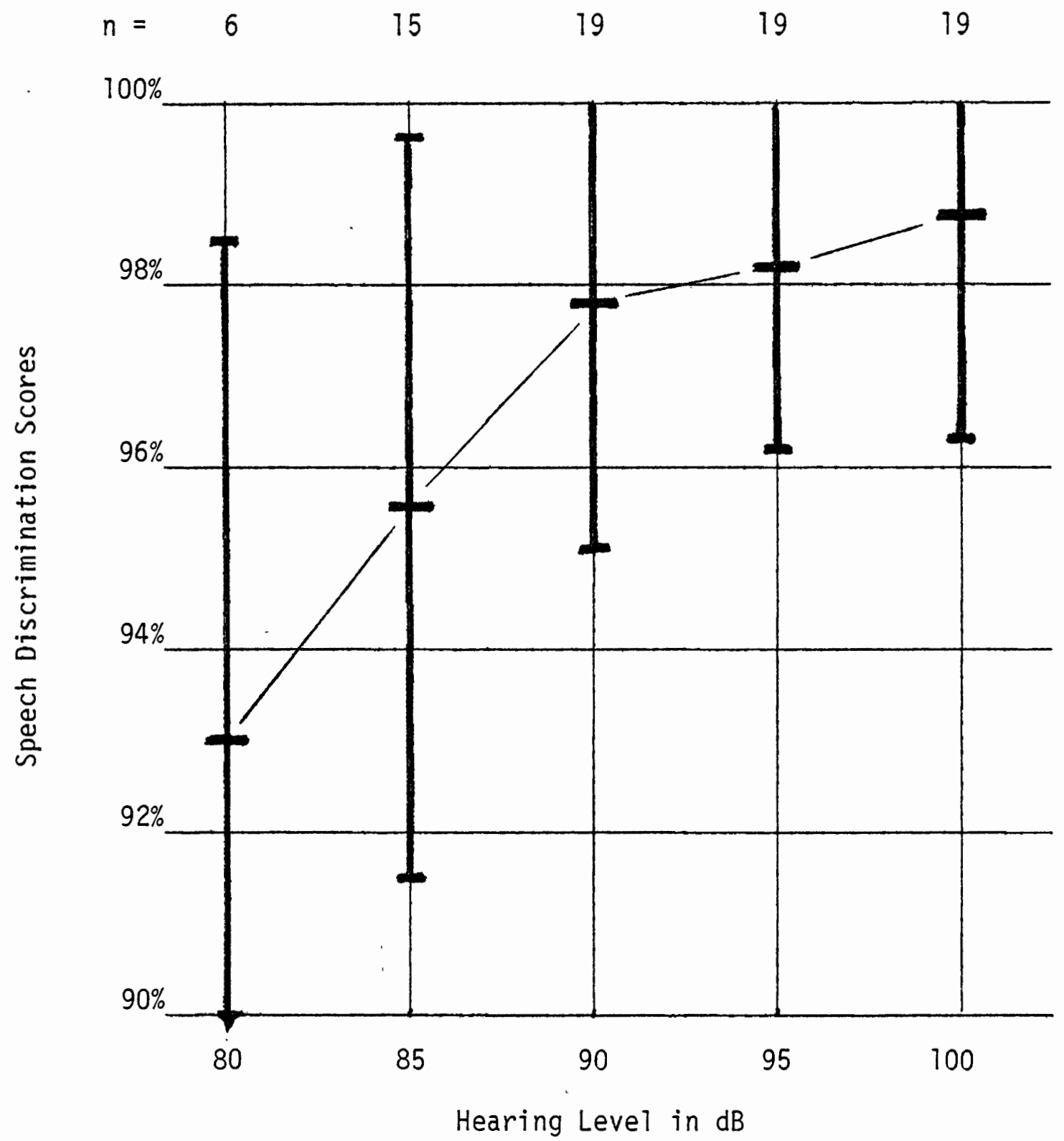

Figure 1. Expected listener performance on bone conducted speech discrimination tests at five points on the audiometer attenuator dial. The means and standard deviations are illustrated. 
deviations of the percentage of correct responses at each of the five experimental hearing levels $(80,85,90,95$ and $100 \mathrm{~dB} H L)$. Only a few normal 1isteners achieved $100 \%$ correct response scores at 80 and $85 \mathrm{~dB}$ HL and some normal listeners scored below $90 \%$, a performance score which is considered to be borderline with respect to the limits of clinical normality (Goetzinger, 1972). Additionally, the sample percentage variances were found to be dramatically greater at the lower intensities ( $80 \mathrm{~dB} \mathrm{HL}=30.00 \%, 85 \mathrm{~dB} \mathrm{HL}=16.68 \%$ ) when compared with the variances at the highest intensity level (100 dB $H L=5.92 \%)$. Another factor which appeared to affect speech discrimination scores was the sensation level at which the bone conducted speech discrimination test was administered to each 1 istener. Table II presents the performances of all experimental ears at each of five sensation levels. These data suggest that the mean percentage of correct responses increases with every $5 \mathrm{~dB}$ increase in intensity from the lowest mean discrimination score (95.78\%) at $40 \mathrm{~dB}$ SL to a peak discrimination score $(98.66 \%)$ at $60 \mathrm{~dB} \mathrm{SL}$.

Since these data indicate that most normal listeners will demonstrate a $55 \mathrm{~dB}$ sensation level at the physical limits of the audiometer it seemed appropriate to statistically examine the differences between the mean percentage of correct responses at $55 \mathrm{~dB} S \mathrm{SL}$ and each of the four other sensation levels $(40,45,50$ and $60 \mathrm{~dB} S \mathrm{SL})$. Statistically, the mean percentage correct responses were significantly poorer $(P<.025)$ at $40 \mathrm{~dB} S \mathrm{SL}$ than at $55 \mathrm{~dB}$ SL. For the other three sensation levels (45, 50 and $60 \mathrm{~dB} S \mathrm{SL})$ these differences were nót statisticaliy: significant. 
TABLE II

PERCENTAGE OF CORRECT RESPONSES IN NORMAL LISTENERS'

BONE CONDUCTED SPEECH DISCRIMINATION AT

FIVE SENSATION LEVELS

\begin{tabular}{|c|c|c|c|}
\hline $\begin{array}{l}\text { Sensation } \\
\text { Levels }\end{array}$ & $\begin{array}{l}\text { Sample } \\
\text { Size }\end{array}$ & $\begin{array}{l}\text { Mean } \\
\% \text { scores }\end{array}$ & $\begin{array}{l}\text { Standard } \\
\text { Deviations }\end{array}$ \\
\hline 40 & 19 & $95.78 \%$ & $4.27 \%$ \\
\hline 45 & 19 & $97.47 \%$ & $3.46 \%$ \\
\hline 50 & 19 & $97.68 \%$ & $3.28 \%$ \\
\hline 55 & 15 & $98.40 \%$ & $2.03 \%$ \\
\hline 60 & 6 & $98.66 \%$ & $1.63 \%$ \\
\hline
\end{tabular}


Figure 2 graphically illustrates the means and standard deviations of the percentage correct performances at each of the five sensation levels $(40,45,50,55$ and $60 \mathrm{~dB} \mathrm{SL})$. While it can be seen that some normal 1 isteners achieved a $100 \%$ score at all sensation levels, it can also be seen that three normal listeners achieved a score of $90 \%$ or less, the lower limit of clinical normality, when they were tested at a $40 \mathrm{~dB}$ sensation level. It should be noted here that the standard deviation also decreased with every $5 \mathrm{~dB}$ SL increase of intensity. Therefore, it can be demonstrated that there is less variation with each successive $5 \mathrm{~dB} \mathrm{SL}$ increase of intensity. The percentage variation in speech discrimination scores was greatest at $40 \mathrm{~dB} S \mathrm{SL}$ $(17.75 \%)$ and least $(2.67 \%)$ at $60 \mathrm{~dB}$ SL. 


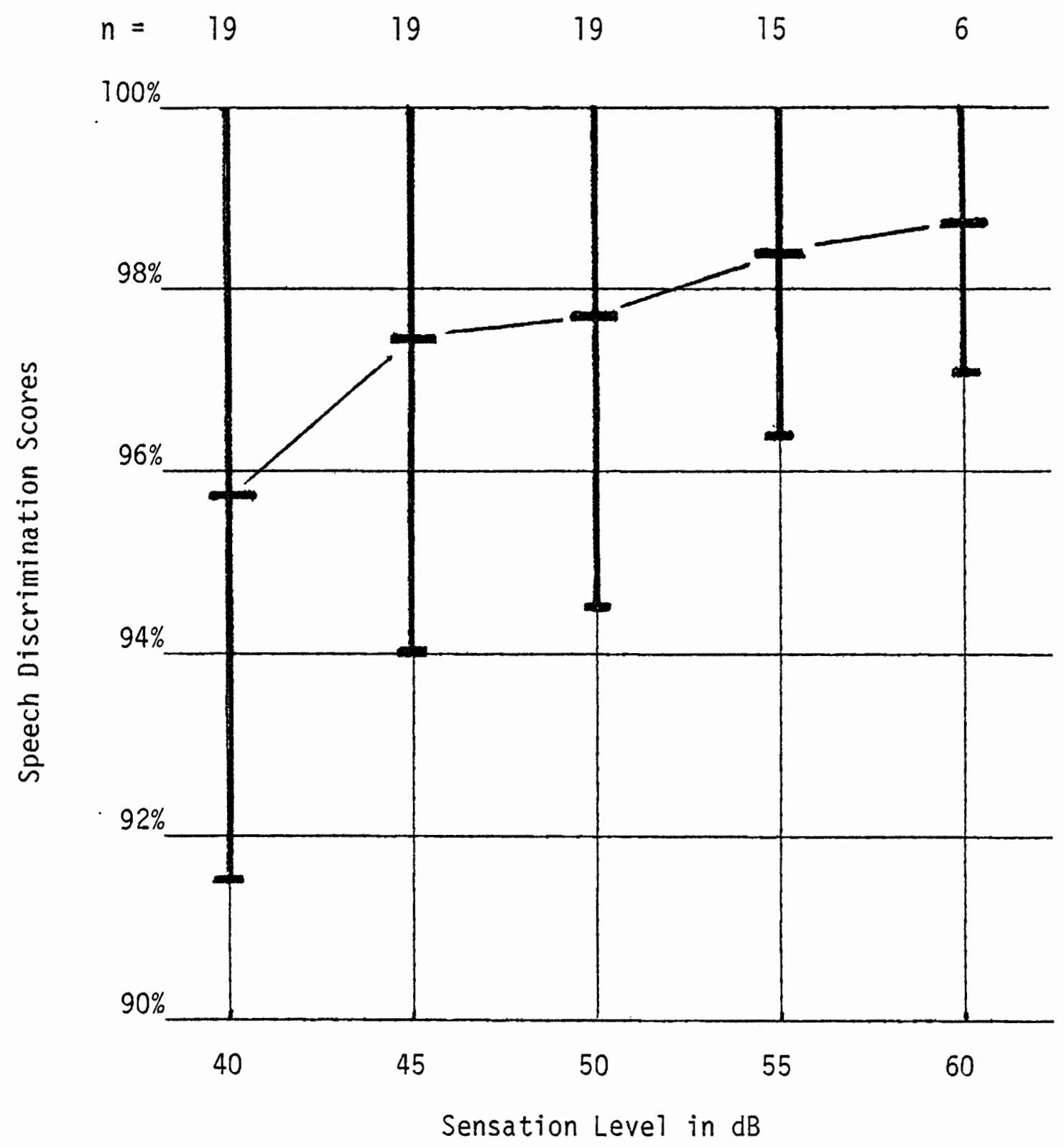

Figure 2. Expected listener performance on bone conducted speech discrimination tests at five sensation levels. The means and standard deviations are illustrated. 


\section{CHAPTER V}

\section{SUMMARY AND CONCLUSIONS}

Summary

When considering the intensity for the administration of bone conducted speech tests with standard clinical equipment (Maico, Model 24-B), this study demonstrates that an $80 \mathrm{~dB}$ HL dial setting should not be utilized. There appear to be three factors which clearly contraindicate the use of an $80 \mathrm{~dB} H \mathrm{HL}$ presentation during bone conducted speech discrimination testing. First, the sample variance in percentage of correct responses obtained at that dial setting was extremely large $\left(s^{2}=30.00 \%\right)$. Second, only one of the six experimental ears achieved a score of $100 \%$ and the mean percentage score was only $93.00 \%$, suggesting insufficient output for bone conducted speech. Third, it was demonstrated that there was a statistically significant difference $(P<.005)$ between the mean percentage of correct responses obtained at $80 \mathrm{~dB} \mathrm{HL}$ and those obtained at $100 \mathrm{~dB} \mathrm{HL}$.

Similarly, at the $85 \mathrm{~dB}$ hearing level only two of the 15 experimental ears achieved a $100 \%$ speech discrimination score, and the mean percentage of correct responses was also fairly low (95.60\%) from a clinical standpoint. Again, the sample variance $\left(s^{2}=16.68 \%\right)$ was large and a statistically significant difference $(P<.025)$ was demonstrated between the mean percentage of correct responses. obtained at $85 \mathrm{~dB} H \mathrm{HL}$ and those obtained at $100 \mathrm{~dB} \mathrm{HL}$. This suggests that the 
audiometer output may also be insufficient for bone conducted speech testing with an $85 \mathrm{~dB} H \mathrm{HL}$ dial setting.

When considering the intensity levels between $90 \mathrm{~dB}$ and $100 \mathrm{~dB}$ $H L$, determining the most appropriate level for bone conducted speech is more difficult to clarify. It appears that the intelligibility for speech improves with each $5 \mathrm{~dB}$ increase in intensity to the physical limits of the audiometer (100 dB HL). However, only minor differences were noted in the mean percentage of correct responses at the three highest intensity levers $(90,95$ and $100 \mathrm{~dB} \mathrm{HL})$, and the present data did not clearly support the possibility that intelligibility for bone conducted speech improves with increased intensity at these levels. The data do suggest a trend in this direction, although the lack of sensitivity in the discrimination measure employed and the smaliness of the sample in the present study cumulatively dictate caution in interpreting this result.

Since the bone conducted speech reception threshold value for the equipment used in this experiment was $45 \mathrm{~dB} \mathrm{HL}$ and the physical limit of the equipment was $100 \mathrm{~dB} H \mathrm{HL}$, there is an effective range of $55 \mathrm{~dB}$ for bone conducted speech testing. That is, most normal listeners would be expected to hear bone conducted speech at a $55 \mathrm{~dB}$ sensation level when such tests are delivered at the 1 imits of the audiometer. Additionally, subjects with a measurable sensorineural hearing loss would be expected to realize a commensurate reduction in their sensation level for bone conducted speech tests at the limits of the audiometer. Therefore, it becomes necessary to consider the expected speech discrimination scores of the normal population at specific sensation 
Tevels (dB SL).

The data for each of the five sensation levels considered (40, $45,50,55$ and $60 \mathrm{~dB} S \mathrm{SL}$ ) are very similar to the data obtained for the hearing levels. That is, an improvement was seen in the mean percentage of correct responses with each $5 \mathrm{~dB}$ increase in intensity from a low mean performance score of $95.78 \%$ at $40 \mathrm{~dB}$ SL to an optimal mean performance score of $98.66 \%$ at the highest sensation level considered $(60 \mathrm{~dB} S L)$.

Since $55 \mathrm{~dB}$ SL is the maximum level expected to be used with normal listeners, the difference between the mean percentage of correct responses at $55 \mathrm{~dB} S L$ and each of the other four sensation levels was examined statistically and found to be significant $(P<.025)$ at $40 \mathrm{~dB}$ $\mathrm{SL}$. On the basis of this data, a $40 \mathrm{~dB}$ sensation level is probably inappropriate for bone conducted speech discrimination testing. However, the fact that significant differences could not be measured at the three remaining sensation levels $(45,50$ and $60 \mathrm{~dB} \mathrm{SL})$ even though measurable differences were apparent at each of these sensation levels, does not rule out the possibility that bone conducted speech discrimination scores will improve with increased intensity. But rather, it suggests that the present speech discrimination test, which is of clinical value, may not be refined enough to measure appreciable differences in the performances of normal listeners. Additionally, such differences, if they indeed exist, may be more readily apparent in the performance scores of pathological listeners. Therefore, it is appropriate to consider the utility of each sensation level from a clinical standpoint where the objective for the practicing audiologist is to 
choose a sensation level which provides optimal listening conditions.

On the basis of these data, optimal speech discrimination scores were obtained at the highest sensation level (60 dB SL) with the scores at the adjacent lower sensation level ( $55 \mathrm{~dB} S \mathrm{SL}$ ) being comparable. Additionally, it should be noted that the tests administered at $60 \mathrm{~dB}$ SL were done at the limits of the audiometer (100 dB HL) for those 1 isteners who were able to achieve that level and the discrimination tests for most of the $55 \mathrm{~dB}$ SL group were also administered at the $1 \mathrm{i}$ mits of the audiometer. These data suggest that $100 \mathrm{~dB} H \mathrm{HL}$ may be the intensity of choice for the administration of all bone conducted speech discrimination testing, a finding which is supported by the data of Barry and Gaddis (1978) who reported measurably less harmonic distortion at $100 \mathrm{~dB} \mathrm{HL}$ than at higher intensity levels. While harmonic distortion is probably not a significant artifact in cases demonstrating normal or near normal cochlear reserve, systemic non-linearity may contribute significantly toward the degraded performance of sensorineural cases.

Thus, in terms of sensation levels, poor bone conducted speech discrimination performance might be expected at $40 \cdot \mathrm{dB}$ SL and less than optimal performance at 45 and $50 \mathrm{~dB}$ SL. This suggests that clinical bone conducted speech discrimination tests may be administered at these three levels with validity when the response scores fall within the $1 i$ mits of clinical normality. However, bone conducted speech discrimination testing should be clinically appropriate without qualification when a 55 or $60 \mathrm{~dB}$ sensation level is utilized on similar equipment. The practicing audiologist should, therefore, be able to confidently 
predict the postoperative air conducted speech discrimination outcome whenever bone conducted speech discrimination scores are normal and the non-test ear has been effectively masked.

Finally, the results of the present study suggest several areas for future research. In this study, it was most appropriate to utilize a speech discrimination task which is comparable to the discrimination tests commonly administered in the clinic. Although, the results of this study support the possibility that bone conducted speech discrimination improves with increased intensity for either hearing levels or sensation levels, a more sensitive discrimination test and a larger experimental sample could provide more definitive intermediate values. Additional1y, while it was beyond the scope of the present study to address the issue of pathological listeners directly, the experimental population could be expanded to include large groups of listeners with known combinations of conductive and sensory lesions where less than optimal performance would be expected. Further, while a direct relationship is purported to exist between the preoperative bone conducted speech discrimination scores and the postoperative air conducted discrimination scores of otoscierotic patients, the exact relationship between air and bone conducted discrimination scores has not been established for other pathological ears. If a direct relationship could be established, bone conducted speech tests may prove to be an appropriate clinical tool for many other observations.

\section{Conclusions}

The purpose of this study was to investigate the effects of 
increased intensity on a normal 1istener's bone conducted speech discrimination ability utilizing standard audiological equipment. The NU-6 word lists were utilized to test the bone conducted speech discrmination skills of ten normal hearing subjects, 21 to 30 years of age, on standard clinical equipment. Both the hearing levels (db HL) and the sensation levels ( $\mathrm{dB} S \mathrm{SL}$ ) of the test administration were considered. In general, it was found that $100 \mathrm{~dB} H \mathrm{HL}$ is the most appropriate audiometer dial setting for the administration of bone conducted speech discrimination tests even though comparable speech discrimination scores may be obtained with a $95 \mathrm{~dB}$ HL dial setting. While it appears that the most appropriate sensation levels for the administration of bone conducted speech discrimination tests are 55 and $60 \mathrm{~dB} \mathrm{SL}$, most normal listeners can be expected to achieve only a $55 \mathrm{~dB}$ sensation level at the limits of the audiometer (100 dB HL). Further, when bone conducted speech discrimination tests are administered at a sensation level of less than $55 \mathrm{~dB}$, the results may be compromised by the larger variances found in the normal hearing sample. Therefore, it was recommended that the practicing audiologist accept bone conducted speech discrimination results as valid only when the scores obtained at 40 , 45 and $50 \mathrm{~dB}$ sensation levels are within the limits of clinical normality ( $90 \%$ or better). Finally, it was concluded that more research is needed in the area of bone conducted speech discrimination testing in order to support the hypothes is that bone conducted speech discrimination scores vary as a function of intensity; delineate the efficacy of bone conducted speech tests under a wider variety of pathological conditions; and more clearly define the relationships between air and 
bone conducted speech discrimination testing. 


\section{REFERENCES}

American National Standards Institute, Specification for an Artificial Head-Bone for Calibration of Audiometer Bone Vibrators. ANSI, S3.13-1972, New York: American Nationa 1 Standards Institute, 1972 .

Barry, J.S. and Gaddis, S., "Physical and Physiological Constraints on the Use of Bone Conducted Speech." JSHD, 43:220-6, 1978.

Bavosi, R. and Rupp, R.R., "The Effect of Varied Mastoid Placement of the Bone Oscillator on Threshold Acuity." JAR, 13:247-50, 1973.

Beatie, R.C., Edgerton, B.J. and Svihovec, D.V., "A Comparison of the Auditec of St. Louis Cassette Recordings of NU-6 and CID W-22 on a Normal-Hearing Population." JSHD, 42:60-4, 1977.

Brandy, W.T., "Reliability of Voice Tests of Speech Discrimination:" JSHR, 9:461-5, 1966 .

Carhart, R.C., "Speech Reception in Relation to Pattern of Pure Tone LosS." JSHD, 11:97-108, 1946.

, "Clinical Application of Bone Conduction Audiometry." Arch. Otolaryn., $51: 798-808,1950$.

, "Basic Principles of Speech Audiometry." Acta Otolaryn., $40: 62-71,1951$.

, "Instruments and Materials for Speech Audiometry." Acta Otolaryn., 40:313-23, 1952 .

Carhart, R.C. and Hayes, C., "The Clinical Reliability of Bone Conduction Audiometry." Laryngoscope, 59:1084-1101, 1949.

Carhart, R.C., and Jerger, J.F., "Preferred Method for Clinical Determination of Pure-Tone Thresholds." JSHD, 24:330-45, 1959.

Dirks, D.D., "Bone Conduction Measurements." Arch. Otolaryn., 79:594-9, 1964a.

Dirks, D.D., "American National Standard Specification for an Artificial Head Bone." ASHA, 16:71-3, 1974.

, "Bone-Conduction Testing." In Handbook of Clinical Audiology, Katz, J. (ed), Baltimore: Williams and WiTkins Co., 1978. 
Goetzinger, C.P.., "Word Discrimination Testing." In Handbook of Clinical Audiology, Katz, J. (ed), Baltimore: Williams and Wi $\frac{1 \mathrm{k} i n s}{1972}$ Co., $\frac{\text { A }}{1972 .}$

, "Word Discrimination Testing." In Handbook of Clinical Audiology, Katz, J. (ed), Baltimore: Will iams and Wilkins Co., 1978 .

Goetzinger, C.P. and Proud, G.0., "Speech Audiometry by Bone Conduction." Arch. Otolaryn., 62:632-5, 1955.

Hood, J.D., "Bone Conduction: A Review of the Present Position with Especial Reference to the Contributions of Dr. Gorg von Bekesy." JASA, 34:1325-32, 1962.

Hopkinson, N.T., "Speech Reception Threshold." In Handbook of Clinical Audiology, Katz J. (ed), Baltimore: Williams and Wilkins Co., 1978.

Kasden, S.D. and Robinson, M.D., "Bone Conduction Speech Discrimination in Different Pathologies." JAR, 13:268-70, 1973.

Katz, J. "Clinical Audiology." In Handbook of Clinical Audiology, Katz, J. (ed), Baltimore: Williams and Wilkins Co., 1978 .

Klodd, D.A. and Edgerton, B.J., "Occlusion Effect: Bone Conduction Speech Audiometry Using Forehead and Mastoid Placement." Audiol., $16: 522-9,1977$.

Mendenha11, W., Introduction to Probability and Statistics. Scltuate: Duxbury Press, 1975.

Merrel1, H.B. and Atkinson, C.J., "The Effect of Selected Variables Upon Discrimination Scores." JAR, 5:285-92, 1965.

Robinson, M.D. and Kasden, S.D., "Bone Conduction Speech Audiometry." Annals of Otology, $79: 818-24,1970$.

Sanders, J.W. and Rintleman, W.F., "Masking in Audiometry." Arch. Otolaryn., $80: 541-56,1964$.

Stockdell, K.G., "Speech by Bone Conduction in Diagnostic Audiometry." Audecibel, 23:100-9, 1974.

Studebaker, G.A., "Placement of Vibrator in Bone-Conduction Testing." JSHR, 5:321-31, 1962a. $1962 \mathrm{~b}$. , "On Masking in Bone-Conduction Testing." JSHR, 5:215-27,

, "The Standardization of Bone-Conduction Thresholds." Laryngoscope, 77:823-35, 1967. 
Wilbur, L.A., "Comparability of Two Commercially Available Artificial Mastoids." JASA, 52:1265-6, 1972.

Wilson, R.N., Morgan, D.E. and Dirks, D.D., "A Proposed SRT Procedure and Its Statistical Precedent." JSHD, 38-184-91, 1973. 